\title{
Bilingual Teaching Mode of Engineering Ethics Course in Universities
}

\author{
Di Guan ${ }^{1 \mathrm{a}}$, Hairong $\mathrm{Mi}^{1 \mathrm{~b}}$, Chunli Wang ${ }^{1 \mathrm{C}}$, Kun Zhang ${ }^{2}$, Fanli Zeng ${ }^{1}$, Yuanqiang \\ $\mathrm{Bi}^{1}$, Lisi Duo ${ }^{1}$ and Yanru Liao ${ }^{1}$ \\ ${ }^{1}$ College of Aerospace and Civil Engineering, Harbin Engineering University, Harbin, 150001, \\ Heilongjiang, China \\ ${ }^{2}$ College of Power and Energy Engineering, Harbin Engineering University, Harbin, 150001, \\ Heilongjiang, China \\ aguandi@hrbeu.edu.cn, bmihairong@hrbeu.edu.cn, 'spring555555@126.com
}

Keywords: Engineering ethics, Bilingual teaching, Coupled mode design, University education, Excellent engineers training plans

\begin{abstract}
In engineering activities, people must integrate the sustainable development concept and the scientific development concept into their views, so the engineering ethics education is necessary for the engineering talent cultivation in universities. Relying on professional courses and related practice, this paper designed the coupling teaching model of "engineering ethics education" and "bilingual education" and reviewing its effectiveness. The study aimed to introduce the personal responsibility and obligation of engineer and to form engineering ethics for students, meanwhile to improve the student's professional accomplishment and the internationalization level of the course.
\end{abstract}

\section{The Significance and Necessity of Engineering Ethics Education in Universities}

Engineers take responsibilities to the social environment, for which they should not only consider the contemporary person interests and effective promotions of the healthy society development, but also care about the survival foundation for future generations and other species[1]. Therefore, carrying out the engineering ethics education reasonably and effectively in universities may have continually strong influence on the engineer cultivation, that accord with the own conditions and development planning of universities. It should satisfy the economic construction needs for countries and industries; and be the supplement of technological progress and social development as well[2][3].

Based on the relevant professional courses, this paper introduced overseas professional teaching materials, and designed coupling teaching model of "engineering ethics education" and "bilingual education" around engineers' personal responsibility and obligation and reviewed its effectiveness. By reasonable organization of teaching contents and designed catalytic students' study efficiency, this research focused on shaping the ethical values of engineering students in the value choice of the transformation from technological to reality productivity, in the humanities concern of engineering education, in the ethics following up of project constructions, and in moral self-discipline in the project management. Meanwhile, the bilingual environment was provided to strengthen English language abilities and to improve the international awareness of college students. This coupling teaching model was aimed to improve the students' professional attainment and the course's internationalization level for training comprehensively innovative talents who may serve the society by person responsibility with higher humanities accomplishment and solid professional foundations[4][5].

Results of this paper conforms to the " Excellent Engineers Training Plans" of the 21st century, namely cultivating new engineering subjects who should have the engineering conscience and the sustainable development concept[6][7]. The principle significance of this paper is beneficially to promote the harmony between engineering and environment, as well as human and nature. 


\section{The Integration of Bilingual Teaching in Engineering Ethics Education}

Bilingual teaching can be fully embodied the characters of research and innovation in university education[8]. Integration of bilingual education into the professional teaching mode is beneficial for students to master academic frontiers and current trends. Hence, the students may adopt needs of international market effectively and expand their career opportunities finally[9][10]. For this reason, by the research of engineering ethics training, this paper combined engineering ethics course with bilingual training to establish the "Inquire \& Involve" teaching mode which possesses engineering characteristics, and to explore its effectiveness connectedly.

During the teaching process, this research constructed two core contents as "Inquire" and "Involve"; adjusted key knowledge and difficulty levels according to students' feedback timely and summarizes the practice effect to modify the teaching plan. As one of core contents, inquiry teaching is a discuss-based teaching method to explore the problem as a guide, which is an interactive learning path for students to study problems with teachers or experts. Inquiry teaching adopts the two-way communication between teaching and learning to avoid the breaking of them and inertia in the teaching process, which introduces more initiative in students' learning. And Participatory teaching, another core content, is student-centered teaching method, which emphasizes students' active in exploration and discovery of knowledge, and in construction of knowledge meaning as well. In fact, in this process, students play the main role to summarize scientific research ideas, combine theory with practice, and improve their research ability finally; while the teacher plays the guiding role.

In this paper, the Chinese/English bilingual experimental teaching was supported by the professional courses "Engineering Ethics". According to the unity frontier and practicability, the lecture contents were selected from the originally English textbooks and materials composed by famous experts. The contents choice laid emphasis on covering basic knowledge of engineering ethics, considering the scheduling and requirements in the actual teaching and students demand situations. Arranged in the form to facilitate the needs of teaching and students' self-study, this lecture contents set problem sets behind each chapter to guide the concentrated thinking of students concerned with how to use learned basic principle to analyze the engineering ethics problems on the purpose of solving ethical dilemmas. To study using both mother tongue and English thinking can train students to be able to easily interpret ideas according to research and communication objects.

\section{Design of The Coupled Teaching Mode}

This paper designed the teaching mode which coupling the engineering ethics education and bilingual education to conduct the specialized course teaching and concepts penetrating throughout the civil engineering discipline[11]. Depending on active construction of practice platform, this research presented two teaching processes as "problem-centered" and "student-centered", focusing on the ethical dilemmas and responsibility conflicts which might be encountered by engineers in the engineering practice. This coupled teaching mode aims to solve the application of engineering ethic criterion in real environment, and to promote engineering ethics education in the college students completely.

1. Teaching mode of specialized course improvement: Developed engineering ethics course relying on civil engineering specialty and made the teaching plan and outline. The teaching contents were mainly summarized as: (1) proficient in identifying moral problems and moral issues in engineering; (2) understand, clarify and evaluate the arguments of the opposing parties in the moral issue; (3) compose a consensus and comprehensive view based on relevant facts; (4) identify alternative answers to moral questions and accept creative solutions to practical difficulties; (5) accurate use of universal ethical language.

In teaching sections, students were encouraged to carry out the "simulate teaching", in which students might be effort on case analysis for real or virtual engineering ethics cases by conducting literature investigation and team discussion, then gave English presentations in the end of working. 
Different to the traditional teaching mode which confined teachers and students in teaching and listening separately, the modified mode allows students became the core of the lecture to improve their literacies on engineering ethics and foreign language skill. The English teaching parts pay attention to interaction with students, which encourage students to speak or answer questions in English, besides oral communication of main contents during lectures. And multimedia and other teaching aids were used to demonstrate outlines of lectures and images which can help students to deepen their impression and arouse their interest in learning. So that students can improve their English level without affecting the understanding of professional knowledge.

2. Teaching mode of concept infiltration: Students in engineering subject should learning many courses concerned with science and technology except the specialized course of engineering ethics. To infiltrate the engineering ethics concepts into above courses may extend the audience group, which is beneficial for students to understand the connections between engineering ethics and their working fields. This teaching mode can enhance the course influence and optimize the teaching effect. In courses concerned with engineering introduction and theoretical research, the issue of ethical cases is organically integrated into the whole teaching process. The experience of dilemma solving process is benefit for students to identify and deal with the engineering ethical issues, and to improve the engineering ethics consciousness and decision-making ability. This teaching organization should select exploratory contents to develop students thought, then obtain satisfied achievements.

3. Teaching mode of engineering practice: Created practice platform including training sections of project practices, course designs and graduation projects. The hands-on experience get from practice activities, for example, finding dilemmas in field of engineering ethics, is helpful for students to enhance their independent thinking and handle case studies practically. As a result, their external theories of engineering ethics will be transformed internal believes and behaviors.

Above teaching methods have the same purposes of shaping engineering ethics values correctly for students in university. The trainings can help students to hold their society's sense of responsibility and moral sensitivity, when they face to decision-making, design and construction, and project management in the future. When ethical issues arise, these students should make their own judgment and choice, and create a harmonious and stable environment for the development of human society with rigorous scientific attitude and realistic spirit.

\section{Conclusion}

The construction of harmonious society cannot be separated from high-quality engineering talent cultivation, which requires us to set up the correct concept of engineering ethics and social responsibility education. This study of engineering ethics education achieved the international practice mode and professional teaching contents effectively. The coupled teaching mode of "engineering ethics education" and "bilingual education" can guide the values shaping of students and improve engineering ethics training effect feasibly.

At the beginning, this paper selected undergraduate and graduate students of civil engineering profession as objects in practice teaching, and then the research results can be extended within the whole university by adjusting teaching mode and confirming its effectiveness according to the student feedback. By explored effective ways of internationally innovative talents cultivation, this paper establishes "responsibility" and "conscience" as the core content of engineering ethics education and provides a new perspective for the educational reform of engineering ethics in our country.

\section{Acknowledgement}

In this paper, the research was sponsored by the Research Project on Teaching Reform of Harbin Engineering University (JG10217Y07); the Innovation Project of Seven Education in Harbin Engineering University ("Research and Practice on Education Mode of Engineering Ethics Based 
on the Outstanding Engineers Training Plans" ); the Research Project on Teaching Reform of Harbin Engineering University (JG2016BYB06, JG10217Y05); the Innovation Project of Seven Education in Harbin Engineering University ("Practice on the Values Education Mode of Introductory Course Teaching" and ("Research on Approaches and Countermeasures of Restoring the Academic Integrity for Postgraduate Students”).

\section{References}

[1] Ling Zhou, Yanli Sun, Xiaoyan Kang, Returning to the Engineering and Serving the Society: Case Study and Inspiration from American University Engineering Education [J]. TSINGHUA JOURNAL OF EDUCATION, 201132 (6) 117-124.

[2] Haitao Liu, Yuancheng Guo, Construction of work safety course for civil engineering specialty based on social demand[J]. JOURNAL OF ARCHITECTURAL EDUCATION IN INSTITUTIONS OF HIGHER LEARNING, 2012 21(2) 37-41.

[3] Tingting Zhao, Lei Feng, Social Adaptability of Engineering Education in China: Based on the Empirical Study of Engineering Professional Training Objectives[J], Journal of Higher Education, 2016 37(2) 64-73.

[4] Fengru Liu, Research on the cultivation of academic innovation ability of Postgraduates in the perspective of institutional ethics [D], Hebei University, 2016: 32-38.

[5] Tingfeng Liu, Hongyi Li, Keqiang DING, Exploration of Bilingual Teaching Mode in Environmental Soil Science[J], Higher Education Forum, 2011(2) 2 56-58.

[6] Hejun Li, The Ethics Education Strategy of Excellent Engineers in Colleges and Universities[D], Hefei University of Technology, 2012: 14-22.

[7] Research on Social Responsibility Education in the Perspective of Fostering Excellence Engineer[D], Tianjin University, 2014:28-33.

[8] Xianqiang Meng, Kaiying Wang, Mingjun Liao, Research and Practice of the Course Construction of Bilingual Teaching in Civil Engineering in Common Colleges and Universities[J], JOURNAL OF ARCHITECTURAL EDUCATION IN INSTITUTIONS OF HIGHER LEARNING, 2009(18) 6 53-56.

[9] Zhixiang Chen, On Issues Related to Innovation of Bilingual Instruction Mode and Improvement of Teaching Quality[J], Education and Modernization, 2010(94)1 51-55.

[10]Huaijiang Tie, A Study on the View of Engineering Ethics of the Engineering Undergraduates [D], Southwest Jiaotong University,2013:34-52.

[11] Yuan $\mathrm{Yu}$, The engineering education process based on social needs[J], Journal of Nanchang College of Education-Higher Education, 2013 28(12) 95-96. 